\title{
Estudo da utilização de poços de infiltração em um residencial localizado em São Luís/MA
}

Este trabalho tem como finalidade o estudo da possibilidade da aplicação de sistemas de infiltração em regiões que sofrem alagamentos durante o período chuvoso, mais especificamente no Residencial Farol de São Marcos, bairro Turu, São Luís, Maranhão. Como forma de solucionar os problemas da área em estudo, levando em consideração as características do solo, a vazão de projeto estabelecida e o volume do poço dimensionado, foi determinado a quantidade total de poços que seriam necessários para infiltrar toda água proveniente das precipitações. Com os ensaios realizados foi possível observar que o solo possui baixo grau de permeabilidade sendo um dos fatores para que aconteça a percolação da água das chuvas.

Palavras-chave: Escoamento superficial; Solo; Permeabilidade; Sistemas de infiltração; Inundações.

\section{Study of the use of infiltration wells in a residential located in São Luís/MA}

This study has as porpose to study the possibility of applying infiltration systems in regions that suffer flooding during the rainy season, more specifically in the Residencial Farol de São Marcos, Turu neighborhood, São Luís, Maranhão. In order to solve the problems of the study area, taking into consideration the soil characteristics, the established project flow and the well volume dimensioned, it was determined the total amount of wells that would be necessary to infiltrate all the water coming from the precipitations. With the tests performed it was possible to observe that the soil has low degree of permeability being one of the factors for the percolation of rainwater.

Keywords: Surface runoff; Soil; Permeability; Infiltration systems; Floods.

Topic: Engenharia Civil

Reviewed anonymously in the process of blind peer.
Received: 12/08/2019

Approved: 22/11/2019
Danielle Cristina dos Santos Lisboa (iD Centro Universitário Dom Bosco, Brasil http://lattes.cnpq.br/3350912872257730 http://orcid.org/0000-0001-8707-2442 daniellecristinaeng@gmail.com

André Felipe Sousa Veras id

Centro Universitário Dom Bosco, Brasil

http://lattes.cnpq.br/9686537816626911

http://orcid.org/0000-0003-4903-2348

felipe sousav@hotmail.com

Lucas dos Santos Zenkner (ii)

Centro Universitário Dom Bosco, Brasil

http://lattes.cnpq.br/7556110688320963

http://orcid.org/0000-0002-9408-3833

lucaszenkner1@hotmail.com
Matheus Oliveira Sena

Centro Universitário Dom Bosco, Brasil

http://lattes.cnpq.br/6139273453591965

http://orcid.org/0000-0001-5146-2748

matheusosena@hotmail.com

Lucas Nadler Rocha (iD

Instituto Federal do Maranhão, Brasil

http://lattes.cnpq.br/8693441362635767

http://orcid.org/0000-0003-1424-2054

lucasnadlerrocha@hotmail.com

Thiago Ferreira Silva 10

Centro Universitário Dom Bosco, Brasil

http://lattes.cnpq.br/1116610570148063

http://orcid.org/0000-0002-3545-1368

Thiago.silva@undb.edu.br

\section{Referencing this:}

LISBOA, D. C. S.; VERAS, A. F. S.; ZENKNER, L. S.; SENA, M. O.; ROCHA, L. N.; SILVA, T. F.. Estudo da utilização de poços de infiltração em um residencial localizado em São Luís/MA. Engineering Sciences, v.7, n.3, p.27-43, 2019. DOI: http://doi.org/10.6008/CBPC23183055.2019.003.0003

DOI: 10.6008/CBPC2318-3055.2019.003.0003 


\section{INTRODUÇÃO}

Com o aumento da densidade populacional, juntamente com a diminuição de áreas permeáveis disponíveis, tem resultado em cada vez mais na diminuição da quantidade de água que infiltra, tendo como consequência um crescimento na quantidade de fluidos que escoam superficialmente, fazendo assim com que sejam frequentes os aparecimentos de pontos de alagamentos nas cidades, sendo necessário a criação de sistemas de drenagens urbanas de modo a evitar tais problemas (TUCCl et al., 2003). Segundo Ferreira (2016), existe atualmente muitos dispositivos de infiltração que podem ser implantados. Entre eles, os mais conhecidos e de relativa facilidade de construção e manutenção, estão as trincheiras de infiltração, as valas de infiltração, os pavimentos permeáveis e os poços de infiltração.

Dentre as diversidades de sistemas de infiltração disponíveis, para a escolha de qual deve ser implantado em cada cenário, deve haver primeiramente as considerações de alguns fatores determinantes, tais como, os possíveis impactos ambientais, quer seja causado pelo mal dimensionamento ou pela contaminação da água, como também se há disponibilidade de recursos financeiros, tanto para sua construção, quanto para as manutenções, espaço suficiente disponível, de material na região, e especialmente se o que for adotado, será capaz e eficaz como solução para os problemas (BRITO, 2006).

A implantação de qualquer sistema de infiltração deve passar por análises criteriosas de engenharia para avaliar os riscos, como os de erosão interna, colapso estrutural do solo e perda da capacidade de suporte (CARVALHO, 2013, citado por FERREIRA, 2016). Uma das técnicas mais utilizadas é a trincheira de infiltração, a forma construtiva desta varia de acordo com a estética que se quer obter e o local de construção das mesmas. A sua construção é feita a partir da abertura de valas de pequena profundidade e de grande dimensão longitudinal, sendo que esse vazio será preenchido com materiais de diferentes tamanhos e formatos, tais como, areias, britas, concreto magro e outras matérias que facilitem o transporte, e armazenamento da água durante o uso desse sistema (BRITO, 2006).

Com base nisso e com a elevada densidade demográfica em São Luís do Maranhão, realizou-se uma análise do solo de um Conjunto Residencial, pois no período chuvoso há um permanente acúmulo de água pluvial em certos pontos do bairro. Com base nisso realizou-se uma investigação dos possíveis fatores que tem favorecido o elevado escoamento superficial nessa localidade, fazendo um estudo especifico do mesmo para determinar a possível implantação de uma trincheira de infiltração.

\section{REVISÃO TÉORICA}

\section{Curva Granulométrica}

As retiradas das amostras foram realizadas em campo, teve como embasamento a NBR 9603:2015, que de acordo com as condições no terreno orienta o modo de coletar a amostras deformadas, tais como, as ferramentas utilizadas, qual melhor tipo de trado manual a ser utilizado como também os tipos de recipientes para o condicionamento dos solos extraídos e os dados necessários para a identificação.

Utilizou-se da curva de granulometria sendo que nela é retratada dois tipos de ensaios de 
granulometria, o ensaio de peneiramento e o de sedimentação, as porcentagens de grãos retidos durante o processo de peneiramento e os intervalos de diâmetros para os quatro tipos de solos básicos. O tipo de ensaio granulométrico a ser realizado está relacionado ao tipo de solo e suas dimensões.

A classificação dos grãos no ensaio baseada no autor Caputo (1988), os grãos são classificados de acordo com a predominâncias dos tamanhos presentes nos solos, que são obtidos através do ensaio de peneiramento, identifica-os como, pedregulho - conjunto de partículas cujas dimensões (diâmetros equivalentes) estão compreendidas entre 76 e $4,8 \mathrm{~mm}$; areia, entre 4,8 e 0,05 mm; silte, entre 0,05 e 0,005 $\mathrm{mm}$; argila, inferiores a 0,005 $\mathrm{mm}$.

\section{Amostragem e ensaio de peneiramento}

Para realização do ensaio de peneiramento e dos limites de consistência de um solo, deve-se ser ter primeiramente a preparação da amostra que seguem as Norma Brasileira NBR:6457, que se tem duas maneiras de iniciar o processo de preparo, uma na qual é feita a secagem prévia da amostra, expondo a mesma ao ar livre, e a segunda é sem a secagem prévia, sendo que em ambas é realizado um processo de homogeneização das amostras.

$\mathrm{Na}$ preparação das amostras em que são feitas as secagens prévias, após a secagem e feito o desmanche das partículas maiores, é retirado uma parcela e passada na peneira de malha com abertura de $76 \mathrm{~mm}$ e é feito do descarte do material que ficar retido. Do material passante, com base nas dimensões das maiores das partículas observadas na amostra, é retirado uma massa mínima para assim se dar início ao processo de peneiramento.

\section{METODOLOGIA}

\section{Local de Estudo}

Este estudo teve sua realização na localidade do Conjunto Residencial Farol de São Marcos, que fica localizado no Bairro do Turu, na cidade de São Luís, Maranhão. O local a ser analisado sofre com problemas de enchentes em todo período chuvoso, possivelmente devido a muitos fatores, tais como, a falta de planejamento das construções dos moradores que lá residem, a ineficácia dos sistemas de microdrenagem existente, quer seja pelo incorreto dimensionamento, por obstrução do trajeto a ser percorrido pela água, ou também, devido a sua inexistência, além das características do solo serem desfavoráveis para uma qualidade em relação a permeabilidade do mesmo, prejudicando assim a infiltração da água proveniente das precipitações.

O estudo mais aprofundado da região, fez com que surgisse a necessidade de um estudo que auxiliasse na infiltração da água pluvial, sendo relevante para a população que por ali reside e que há a necessidade de locomoção com conforto e segurança. Na Figura 1 abaixo podemos observar um ponto que ocorre os principais alagamentos no período chuvoso. 


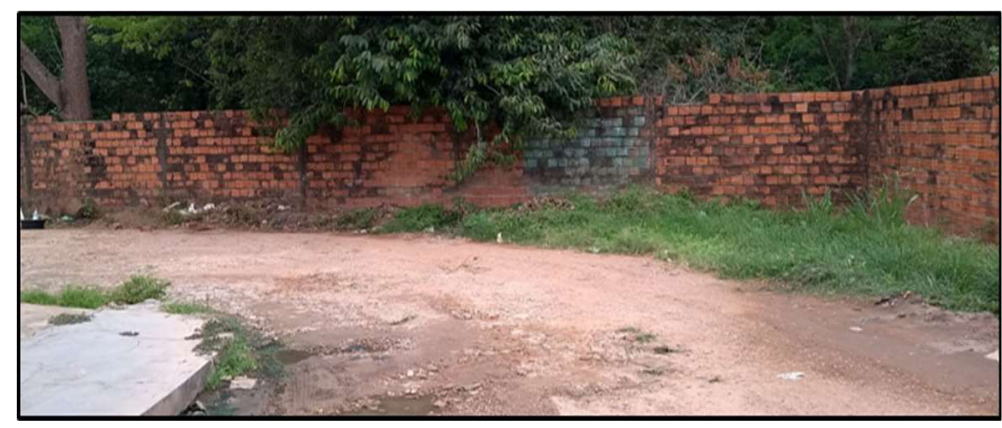

Figura 1: Localização dos alagamentos.

Na Figura 2 a seguir são demonstradas as ferramentas utilizadas para escavação, no lado esquerdo da mesma, que são a pá e a cavadeira articulada e do lado direito, os sacos de polipropileno que foram usados para o armazenamento das amostras de solos proveniente das escavações.

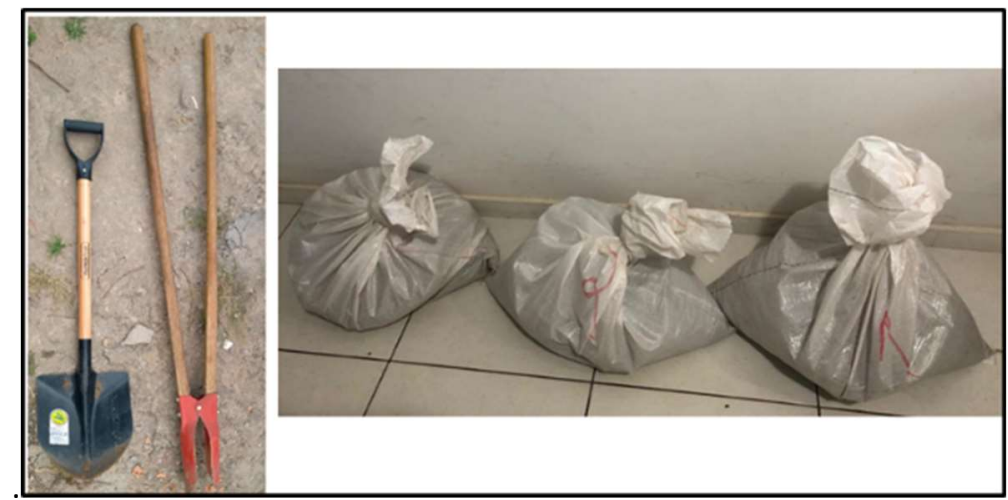

Figura 2: Equipamentos de perfuração e armazenagem.

Com base na NBR 13969:1997, foram feitos a quantidade mínima de três furos, sendo que, como o mesmo item fala, a profundidade final de cada escavação deve ser a mesma na qual futuramente será a baseada no sistema de infiltração, que no caso da experimentação em campo, foram adotados com 1,40 metros.

Cada cava teve um afastamento de 2 metros de distância entre cada eles, e com isso foram perfurados continuamente com um diâmetro aproximado de 50 centímetros até a profundidade de 1,10 metros, que ao se chegar nessa profundeza, já como forma de preparo para o futuro experimento, foi continuado a escavação com o diâmetro de 0,15 metros e começou-se a coleta das amostras até a cota de 1,40 metros, para serem levadas para a análise em laboratório.

As amostragens recolhidas foram acondicionadas nos sacos de polipropileno e identificados com numerações de cava, sendo elas a cava 1, cava 2 e cava 3 e foram acomodados em local cedo e arejado, de modo a não haver perda excessiva de umidade, até o momento de serem levados ao laboratório. A NBR 9603:2015, retrata que a massa mínima de amostra a ser coletada para ensaios laboratoriais como sendo uma quantidade de $4 \mathrm{~kg}$. Com isso, para cada escavação foi retirada aproximadamente $20 \mathrm{~kg}$ de material, de modo a prevenir acontecimentos futuros de necessidade de novas experimentações a serem realizas e condicionadas nos sacos separadamente, conforme a Figura 2 acima. 


\section{Análise dos Dados}

Inicialmente foi realizado os experimentos in loco, de modo a determinar a taxa de percolação do solo. A priori foi feito a análise tátil e visual do solo, de modo a classificá-lo empiricamente e que na NBR 6484:2001 fala como fazer essa classificação preliminar. O solo utilizado para essa análise foi o escavado nos últimos 30 centímetros, de modo se obter uma camada com características mais aproximadas das abaixo dela. Foi possível a observação a olho nu de seus grãos, ou seja, possuem partículas maiores que 0,1 mm, isso em todos os três solos. Ao serem pressionados sobre a palma da mão, demonstraram uma certa aspereza e mais separação dos grãos, o que indica baixa consistência. Com base na base na mesma norma, diante da visualização dos grãos e das elevadas rugosidades das amostras, todos os três foram determinados de forma empírica como arenosos. A Figura 3 demostra o tipo de solo encontrado.

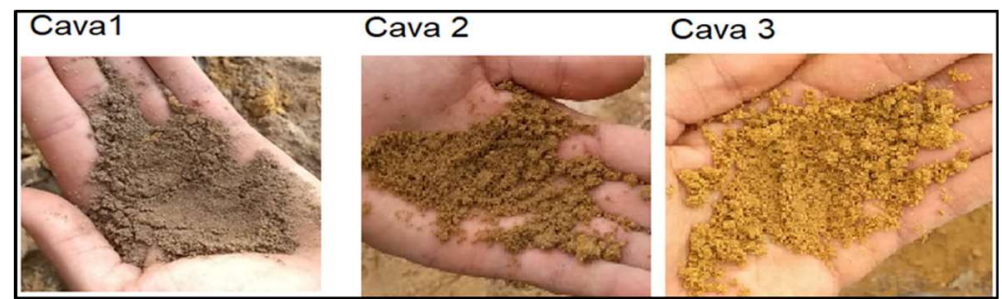

Figura 3: Análise tátil e visual dos solos.

Ao serem finalizadas as escavações, foram colocadas uma camada de brita com $5 \mathrm{~cm}$ de altura em cada cava, como determinado pela NBR 13969:1997. Posteriormente, segundo a mesma norma, foi feito a primeira etapa do ensaio de taxa de percolação do solo, na qual, todas as cavas foram enchidas e cronometradas o tempo de infiltração, como após 10 min nenhuma havia finalizado o processo de percolação, e o solo ter sido classificado como arenoso, teve-se início a etapa de 4 horas continuas de saturação do solo, sendo mantido em cada escavação um nível constante de $30 \mathrm{~cm}$ de altura durante etapa.

No primeiro dia de ensaio foram feitas apenas as escavações e o procedimento de saturação do solo. No segundo dia de ensaio, como a norma anterior determina que a inicialização do ensaio de taxa de percolação do solo deve ser no intervalo inferior a 30 horas posterior a finalização da saturação, teve seu início após $19 \mathrm{~h}$.

No segundo dia de ensaio, como descrito na norma, cada escavação teve o processo de enchimento com água possuindo uma cota de $15 \mathrm{~cm}$ acima da camada de brita, e com isso foram registradas as medidas de redução de nível a cada $30 \mathrm{~min}$. Sempre passado esse tempo, era colocado água de modo a retornar aos $15 \mathrm{~cm}$ iniciais. O procedimento se sucedeu após passado o tempo de $30 \mathrm{~min}$, a diminuição da altura fosse inferior a 1,5 cm, em seguida sendo repetido três vezes o processo de enchimento e descida de nível e anotadas as medidas reduzidas no tempo estipulado. Na Figura 4, do lado esquerdo é demonstrado como foi realizado o posicionamento da régua para medição das cotas durante o ensaio de percolação e na outra como foi feito a medição durante a cava cheia com os $15 \mathrm{~cm}$ de altura. 

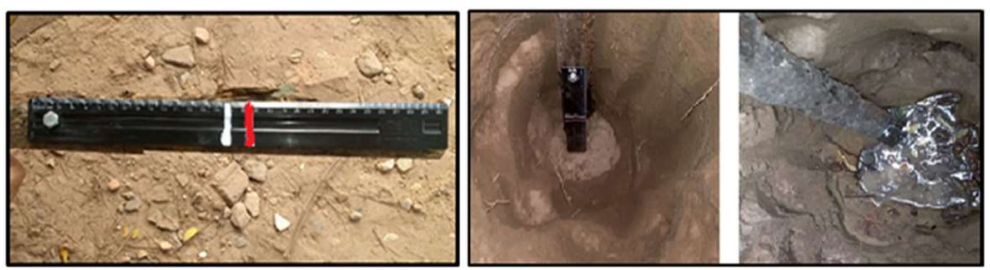

Figura 4: Régua utilizada para medição das cotas e ensaio de percolação.

Foram analisadas as características dos solos coletados em campo, analisando suas distribuições granulométricas, seus índices físicos, seus limites de liquidez e limites de plasticidade. As amostras foram retiradas de acordo com a NBR 9603:2015, onde diz a massa mínima de 4 kg de cada amostra de escavação. Com posse dessas massas, foram levadas à estufa com a temperatura interior de $105^{\circ} \mathrm{C}$ por um período de 24h para a secagem e determinação da massa do solo seco, para assim obter a umidade do solo em seu estado natural.

Posteriormente a retirada das amostras da estufa seguem a NBR 6457:2016, foi realizado o processo de quarteamento em cada uma e retirado duas extremidades opostas para poderem ser destorroadas e homogeneizadas. Com as amostras já uniformes, foram passadas na peneira com abertura de malha de $2 \mathrm{~mm}$ até a obtenção de $1 \mathrm{~kg}$ para cada uma e assim dar início ao ensaio de peneiramento.

Com posse das amostragens necessárias, foram utilizadas as peneiras com malha de 1,2mm, 0,6mm, $0,42 \mathrm{~mm}, 0,3 \mathrm{~mm}$ e $0,075 \mathrm{~mm}$ para o peneiramento. Os ensaios se deram com a agitação mecânica das peneiras por um tempo de 1 minuto. Após finalizado o peneiramento, foram pesadas as massas de solo retidas em cada peneira, sendo que em nenhum dos três ensaios teve uma perda superior a $3 \%$ do valor total inicial, que é o máximo aconselhável. A Figura 5 demostra o processo de quarteamento das amostras.

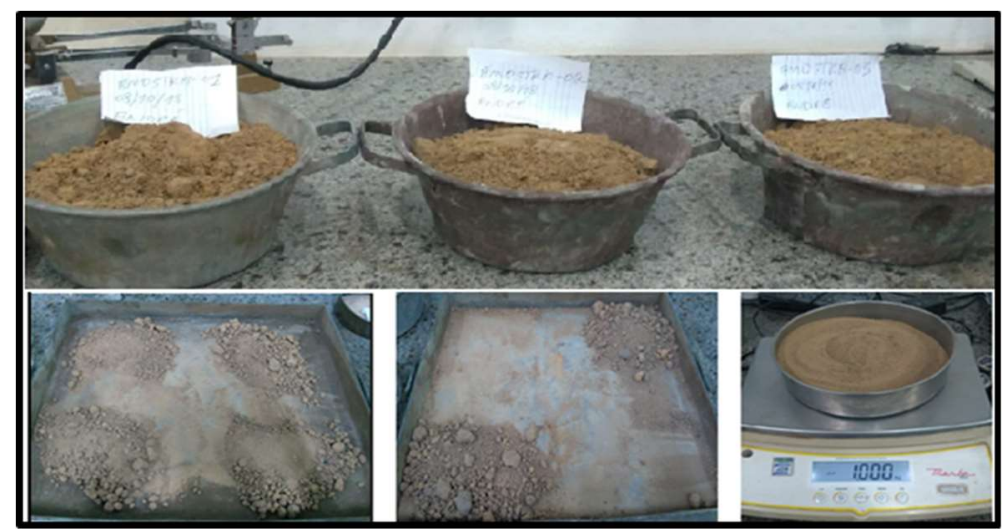

Figura 5: Processo de quarteamento e separação de amostras para ensaios.

Com a finalização do processo de peneiramento e pesagem das amostras retiras em cada peneira, os mesmos solos foram passados na peneira de abertura $0,42 \mathrm{~mm}$, de modo que foram coletados $200 \mathrm{~g}$ passados para a realização dos ensaios de limites de liquidez e limites de plasticidade dos mesmos. Os ensaios dos limites de liquidez se sucederam até a obtenção de três valores para cada amostra das cavas. Inicialmente, foi realizado o umedecimento de parte do no recipiente, durante 15 minutos, até sua uniformização, após isso, foram colocados no aparelho de Casa Grande, aberto a ranhura e iniciado o processo de golpes até o fechamento das aberturas em um intervalo de 15 a 35 golpes, sendo pretendido o valor de 25 golpes. Posteriormente a cada finalização de golpeamento, pare do solo presente no aparelho foi coletado e 
condicionado em capsulas metálicas, pesados antes e depois de serem levados à estufa por 24h, já com a massa seca, para com isso, ser possível conseguir dados de umidade e determinar o valor dos limites de liquidez daqueles solos.

Prosseguindo com os experimentos, foi procurado moldar o corpo para determinação dos limites de plasticidade dos solos, porém não havia o modelo de corpo de prova, o que inviabilizou o procedimento. Os valores dos limites plasticidade acabaram sendo descartados, pois, em nenhuma das amostras teve mais de $30 \%$ passados na peneira de $0,075 \mathrm{~mm}$, o que os desclassificam os solos como predominantemente argilosos (DAS et al., 2014). Na Figura 6 abaixo demostra como foi realizado o ensaio de limite de liquidez em laboratório.

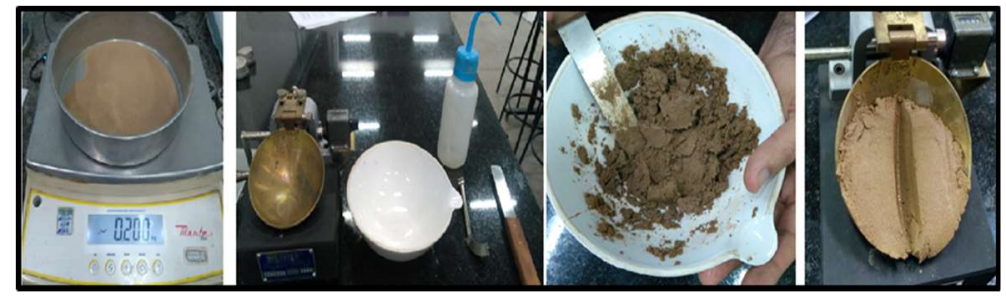

Figura 6: Amostra, equipamentos e ensaio de limite de plasticidade.

Primeiro a coleta dos $200 \mathrm{~g}$ passados na peneira de $0,42 \mathrm{~mm}$, processando-se a adição de água destilada e homogeneização, para início dos golpes.

\section{RESULTADOS E DISCUSSÃO}

\section{Cálculo da Taxa de percolação do solo (K)}

Para a NBR 13969:1997, taxa de percolação média do solo é obtida através da média aritmética dos valores de cada cava em relação ao tempo levado para o a diminuição da cota que ocorreu no último registro, sendo assim, a equação para obter a taxa de percolação média do solo será de acordo com a Eq (1).

$$
K s=\frac{\Sigma k}{n}
$$

Onde ' $n$ ' é a quantidade dos últimos ensaios das escavações realizadas.

De acordo com esse cálculo obteve os valores da Tabela 1 abaixo, os dados coletados nos ensaios realizados nas escavações, como forma de determinação da taxa de percolação daquele solo. Como inicialmente o solo foi classificado como arenoso, com base na NBR 13969:1997, cada perfuração teve sua primeira medição como em todas teve uma redução igual ou menor a $15 \mathrm{~mm}$, foram realizadas mais três medições para cada uma e registrado a quantidade de rebaixamento do nível d'água em um intervalo de 30 minutos.

Tabela 1: Redução do nível nas cavas em cada período.

\begin{tabular}{|c|c|c|c|c|c|c|c|c|}
\hline \multicolumn{9}{|c|}{ ENSAIO DA TAXA DE PERCOLAÇÃO DO SOLO } \\
\hline \multicolumn{3}{|c|}{ CAVA NÚMERO 1} & \multicolumn{3}{|c|}{ CAVA NÚMERO 2} & \multicolumn{3}{|c|}{ CAVA NÚMERO 3} \\
\hline Testes & Tempo (min) & $\begin{array}{ll}\text { Variação } & \text { de } \\
\text { altura }(\mathrm{mm}) & \end{array}$ & Testes & Tempo (min) & $\begin{array}{ll}\text { Variação } & \text { de } \\
\text { altura }(\mathrm{mm}) & \end{array}$ & Testes & Tempo (min) & $\begin{array}{ll}\text { Variação } & \text { de } \\
\text { altura }(\mathrm{mm})\end{array}$ \\
\hline $1^{\circ}$ & 19 & 15 & $1^{\circ}$ & 30 & 15 & $1^{\circ}$ & 21 & 15 \\
\hline $2^{\circ}$ & 30 & 10 & $2^{\circ}$ & 30 & 11 & $2^{\circ}$ & 30 & 9 \\
\hline $3^{\circ}$ & 30 & 5 & $3^{\circ}$ & 30 & 8 & $3^{\circ}$ & 30 & 5 \\
\hline $4^{\circ}$ & 30 & 5 & $4^{\circ}$ & 30 & 7 & $4^{\circ}$ & 30 & 4 \\
\hline
\end{tabular}

Legenda: Foram utilizados 4 testes para cálculo da cava 1, cava 2 e cava 3. 
Com os dados da tabela, podemos observar a relação de percolação entre as cavas de acordo com a Figura 7 abaixo.

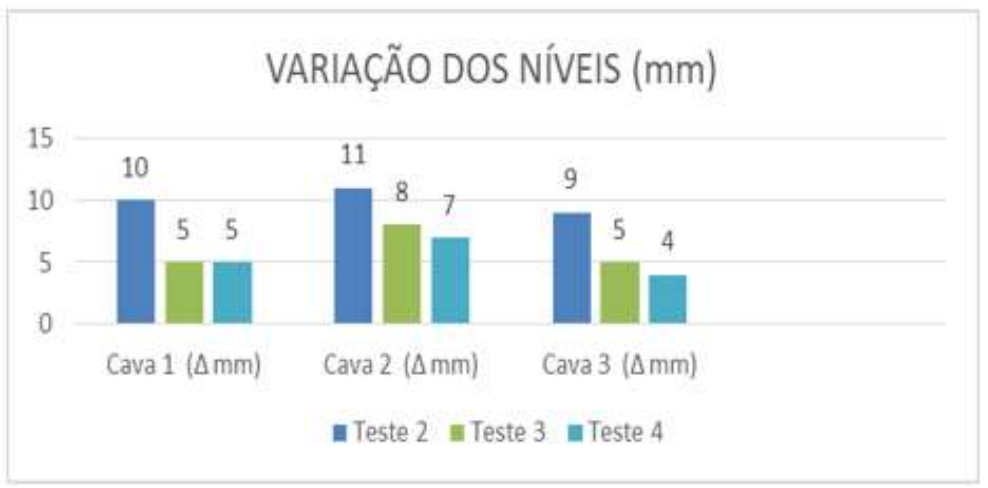

Figura 7: Diminuição das cotas dos níveis nas cavas.

Segundo a mesma norma anteriormente citada, apenas o valor da última medição é considerado para o cálculo das taxas de percolação de cada cava. Sendo assim, o valor do coeficiente de permeabilidade dos solos está na tabela seguinte (Tabela 2).

Tabela 2: Taxa de percolação de cada escavação.

\begin{tabular}{|l|l|l|l|}
\hline \multicolumn{2}{|l|}{ TAXA DE PERCOLÇÃO (K) } \\
\hline & Tempo (min) & \multicolumn{1}{|c|}{ Variação do nível $(\mathbf{m m})$} & Taxa $\mathbf{k}(\mathbf{m i n} / \mathbf{m m})$ \\
\hline Cava 1 & 30 & 5 & 6 \\
\hline Cava 2 & 30 & 7 & 4,3 \\
\hline Cava 3 & 30 & 4 & 7,5 \\
\hline
\end{tabular}

Legenda: Utilização de 3 cavas para determinação do tempo mínimo, variação de nível e Taxa.

Na Tabela acima, tem-se a determinação das taxas de percolação (K) de cada escavação. Nela se demonstra que, a Cava 1 necessita de um tempo de 6 min para que seja infiltrado $1 \mathrm{~mm}$ de lâmina d'água, já a Cava 2 percola $1 \mathrm{~mm}$ em um intervalo de 4,3min e a Cava 3 infiltra $1 \mathrm{~mm}$ em um período de 7,5 minutos. Diante disso, tem-se que no ponto onde está a Cava 3, tem a menor capacidade de infiltração dentre os pontos estudados, o que leva a precisão de maior tempo para redução dos níveis superficiais das águas. De acordo com a NBR13969 :1997, a taxa de percolação média do solo é obtida fazendo-se a média aritmética dos valores de $\mathrm{K}$ de cada escavação, então para o lugar estudado terá como valor de projeto para taxa de percolação, utilizando-se a Equação (2) abaixo.

$$
K s=((6+4,3+7,5) / 3)=5,93 \mathrm{~min} / \mathrm{mm} .
$$

Com a definição do valor da taxa de percolação média (K), terá que a mesma possui um coeficiente de permeabilidade igual a 2,81 x 10-4 cm/segundo. Sendo assim, com base da Tabela 1 como solo está compreendido no intervalo de permeabilidade em que $10-5 \mathrm{~cm} / \mathrm{s}<\mathrm{K}<5 \times 10-3 \mathrm{~cm} / \mathrm{s}$, ele é classificado como um solo com baixa permeabilidade.

\section{Classificação Granulométrica}

Na Tabela 3 são expostos os dados obtidos através do ensaio de peneiramento que foram realizados em laboratório. As amostras são nomeadas de acordo com suas ordens de escavação e suas demarcações no local de colhimento das mesmas. Sendo assim, a Amostra 1 é proveniente da Cava 1, a Amostra 2 da Cava 2 
e Amostra 3 é a retirada da terceira escavação. Nela se tem em relação a cada amostra, a quantidade que ficou retida em cada peneira e suas respectivas porcentagens, de modo que esses valores possibilitem a classificação da distribuição dos grãos pertencentes a elas.

Tabela 3: Resultados do ensaio de peneiramento.

\begin{tabular}{|l|l|l|l|l|l|l|l|l|l|}
\hline $\begin{array}{l}\text { Peneira } \\
(\mathbf{m m})\end{array}$ & \multicolumn{3}{|l|}{ Massa Retida (g) } & \multicolumn{2}{l|}{ Amostra 1 } & \multicolumn{2}{l|}{ Amostra 2 } & \multicolumn{2}{l|}{ Amostra 3 } \\
\hline & $\begin{array}{l}\text { Amostra } \\
\mathbf{1}\end{array}$ & $\begin{array}{l}\text { Amostra } \\
\mathbf{2}\end{array}$ & $\begin{array}{l}\text { Amostra } \\
\mathbf{3}\end{array}$ & \% Retida & \%Acum. & \% Retida & \%Acum. & \% Retida & \%Acum. \\
\hline 1,2 & 104 & 87 & 47 & 10,4 & 10,4 & 8,7 & 8,7 & 4,7 & 4,7 \\
\hline 0,6 & 306 & 246 & 131 & 30,6 & 41 & 24,6 & 33,3 & 13,1 & 17,8 \\
\hline 0,42 & 249 & 305 & 305 & 24,9 & 65,9 & 30,5 & 63,9 & 30,5 & 48,3 \\
\hline 0,3 & 143 & 159 & 225 & 14,3 & 80,2 & 15,9 & 79,8 & 22,5 & 70,9 \\
\hline 0,15 & 131 & 141 & 197 & 13,1 & 93,3 & 14,1 & 93,9 & 19,7 & 90,6 \\
\hline 0,075 & 48 & 45 & 76 & 4,8 & 98,1 & 4,5 & 98,4 & 7,6 & 98,2 \\
\hline Fundo & 19 & 16 & 18 & 1,9 & 100 & 1,6 & 100,0 & 1,8 & 100,0 \\
\hline TOTAL & 1000 & 999 & 999 & 100 & & 100 & & 100 & \\
\hline
\end{tabular}

Legenda: Cálculo da massa retida das 3 amostras, verificando o percentual retido em cada peneira e o percentual acumulado.

Como em nenhum dos três ensaios houve perda de $0,3 \%$ da massa total ensaiada, tendo como perda apenas $0,1 \%$ nas amostras das Cavas 2 e 3, não existiu a necessidade da realização de novos ensaios. Para melhor analisar os resultados do ensaio de peneiramento e determinar de maneira precisa a distribuição dos grãos de cada amostra ensaiada, tem-se a demonstração de seus valores na Figura 8 abaixo.

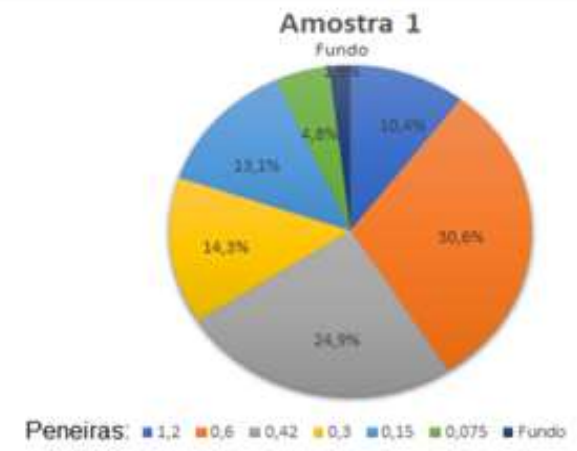

Figura 8: Amostra 1- Porcentagem acumulada em cada peneira.

A Figura 9 demonstra que $87,7 \%$ dos grãos estão compreendidos entre as peneiras de $1,2 \mathrm{~mm}$ e 0,075mm para Caputo (1998), na curva granulométrica nessa classificação de peneiras ele é predominantemente composto de areia. $\mathrm{O}$ autor ainda fala sobre a graduação dos grãos como forma de categorizar um tipo de solo a partir das porcentagens dos grãos presentes, denominado de coeficiente de uniformidade, que é dado pela fórmula $\mathrm{Cu}=\mathrm{d} 60 /$ def. No qual d60 é o diâmetro no qual $60 \%$ da amostra é menor que ele, e que def $\neg$ é o diâmetro que tem $10 \%$ da amostra sendo inferior. Sendo assim, Cu da amostra 1 é, $\mathrm{Cu}=0,42 / 0,15=2,8$, o que significa que o solo possui uma graduação uniforme, ou seja, é bem graduado, fazendo com o que o mesmo seja razoavelmente permeável. 


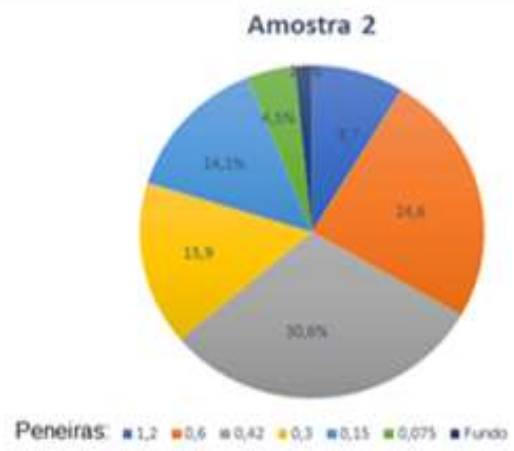

Figura 9: Amostra 2- Porcentagem acumulada em cada peneira.

Como demonstrado no Figura 9 tem-se como passados pela peneira de abertura de 0,075 mm apenas $1,6 \%$, ou seja, $89,7 \%$ dos grãos tem diâmetros entre $1,2 \mathrm{~mm}$ e $0,075 \mathrm{~mm}$, o que o classifica esse solo como arenoso. Em relação ao grau de uniformidade dos grãos presentes na amostra da cava 2 analisada, $\mathrm{Cu}=$ $0,42 / 0,15$, ou seja, $\mathrm{Cu}=2,8$, como $\mathrm{Cu}$ é menor que 5 , o solo tem a disposição de uniformemente, favorecendo com isso, a infiltração no mesmo.

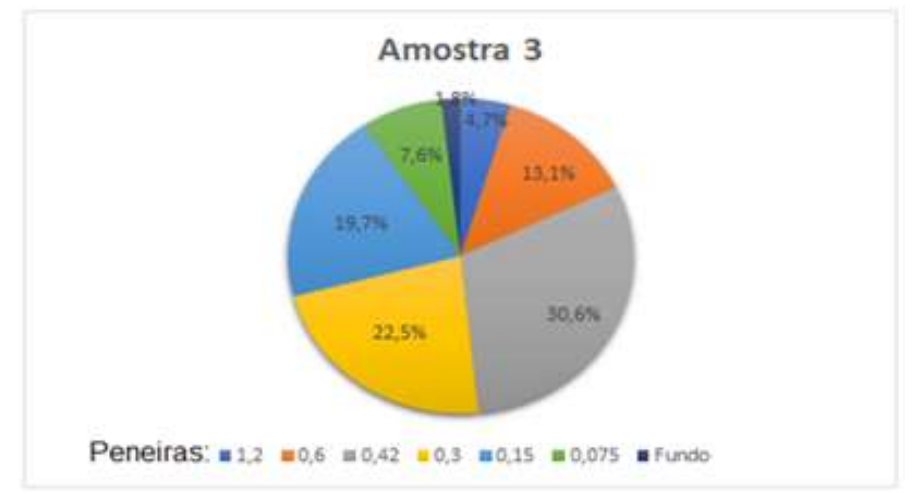

Figura 10: Amostra 3- Porcentagem acumulada em cada peneira.

Com base na Figura 10 idealizado a partir do ensaio granulométrico da amostra da Cava 3, expõe a porcentagem retidas nas peneiras, sendo que $93,5 \%$ são das partículas possuem dimensões compreendidas entre $1,2 \mathrm{~mm}$ e $0,075 \mathrm{~mm}$, o que determina que o mesmo possui predominância de grãos de areia. 0 grau de uniformidade dos grãos $\mathrm{Cu}$, será do valor de 2,8, sendo assim, os grãos presentes no local de coleta da amostra possuem uma graduação uniforme. Diante desses gráficos, é de mais fácil entendimento o porquê da Cava 3 apresentar uma taxa de percolação maior, ou seja, a necessidade de um maior período para infiltração de uma altura da lâmina d'água, isso se dá devido à maior concentração de partículas de silteargila no solo.

\section{Limite de Liquidez e limite de plasticidade}

Após a realização dos ensaios de peneiramento para cava amostra coletada nas escavações, peneirou-se os mesmos materiais ensaiados em uma peneira de $n^{\circ} 40$, que possui abertura de malha de $0,42 \mathrm{~mm}$, de modo a se obter $200 \mathrm{~g}$ de material passante, para assim dar início aos ensaios para determinação dos limites de plasticidade e limites de liquidez. 
Tabela 4: Limites de liquidez de cada escavação.

\begin{tabular}{|c|c|c|c|c|c|c|c|}
\hline \multicolumn{8}{|c|}{ LIMITE DE LIQUIDEZ -CAVA N¹ } \\
\hline Cápsula $n^{\circ}$ & $\begin{array}{l}\text { Peso da Cápsula e } \\
\text { solo molhado (g) }\end{array}$ & $\begin{array}{l}\text { Peso da } \\
\text { Cápsula e solo } \\
\text { seco (g) }\end{array}$ & $\begin{array}{l}\text { Peso da } \\
\text { Cápsula (g) }\end{array}$ & $\begin{array}{l}\text { Peso da } \\
\text { água (g) }\end{array}$ & $\begin{array}{l}\text { Peso do } \\
\text { solo seco } \\
\text { (g) }\end{array}$ & $\begin{array}{l}N^{\circ} \text { de } \\
\text { golpes }\end{array}$ & $\begin{array}{l}\text { Teor de } \\
\text { umidade (\%) }\end{array}$ \\
\hline 1,5 & 48 & 44 & 12 & 4 & 32 & 30 & 12,5 \\
\hline 7 & 44 & 40 & 11 & 4 & 29 & 24 & 13,8 \\
\hline 17 & 39 & 36 & 12 & 3 & 24 & 27 & 12,5 \\
\hline \multicolumn{8}{|c|}{ LIMITE DE LIQUIDEZ -CAVA N² } \\
\hline Cápsula $n^{\circ}$ & $\begin{array}{ll}\text { Peso da } & \text { Cápsula e } \\
\text { solo } & \text { molhado } \\
\text { (g) } & \\
\end{array}$ & $\begin{array}{l}\text { Peso da } \\
\text { Cápsula e solo } \\
\text { seco (g) }\end{array}$ & Peso da Cápsula (g) & $\begin{array}{l}\text { Peso da } \\
\text { água (g) }\end{array}$ & $\begin{array}{l}\text { Peso do } \\
\text { solo seco } \\
\text { (g) }\end{array}$ & $\begin{array}{l}N^{\circ} \text { de } \\
\text { golpes }\end{array}$ & $\begin{array}{l}\text { Teor de } \\
\text { umidade (\%) }\end{array}$ \\
\hline 10 & 36 & 33 & 13 & 3 & 20 & 20 & 15 \\
\hline 11 & 36 & 34 & 13 & 2 & 21 & 22 & 9,5 \\
\hline 13 & 39 & 36 & 12 & 3 & 24 & 25 & 12,5 \\
\hline \multicolumn{8}{|c|}{ LIMITE DE LIQUIDEZ -CAVA N³ } \\
\hline Cápsula $n^{\circ}$ & $\begin{array}{l}\text { Peso da Cápsula e } \\
\text { solo molhado (g) }\end{array}$ & $\begin{array}{l}\text { Peso da } \\
\text { Cápsula e solo } \\
\text { seco (g) }\end{array}$ & Peso da Cápsula (g) & $\begin{array}{l}\text { Peso da } \\
\text { água (g) }\end{array}$ & $\begin{array}{l}\text { Peso do } \\
\text { solo seco } \\
\text { (g) }\end{array}$ & $\begin{array}{l}N^{\circ} \text { de } \\
\text { golpes }\end{array}$ & $\begin{array}{l}\text { Teor de } \\
\text { umidade (\%) }\end{array}$ \\
\hline 0,5 & 39 & 35 & 12 & 4 & 23 & 17 & 17,4 \\
\hline 2 & 41 & 37 & 10 & 4 & 27 & 16 & 14,8 \\
\hline 3 & 40 & 36 & 13 & 4 & 23 & 26 & 17,4 \\
\hline
\end{tabular}

Fonte: Cálculo do limite de liquidez para as 3 cavas.

A Tabela 4 serviu de modo a melhor organizar os dados conseguidos através do ensaio do limite de liquidez, tais como, cada umidade para a quantidade de golpes necessários para o fechamento da fenda no intervalo definido. Com os três valores mínimos de umidades para cada amostra, com base na NBR 6459 :2016, foram construídas imagens que relacionavam a quantidade de golpes para cada teor de umidade, para assim, fazer uma reta de linearidade entre os pontos e definir o valor de umidade para os 25 golpes. De acordo com as Figuras 11, 12 e 13 abaixo temos o limite de liquidez das cavas 1, 2,3.

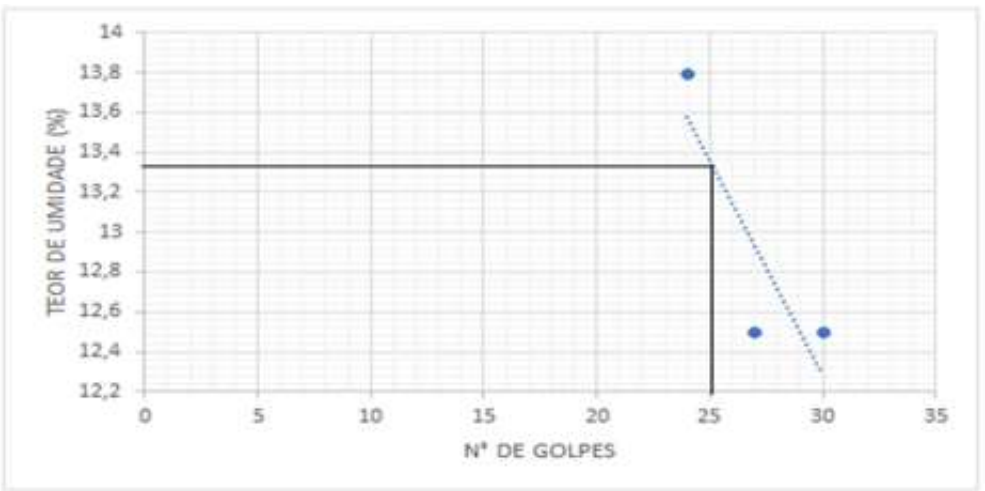

Figura 11: Determinação do limite de liquidez da Cava 1.

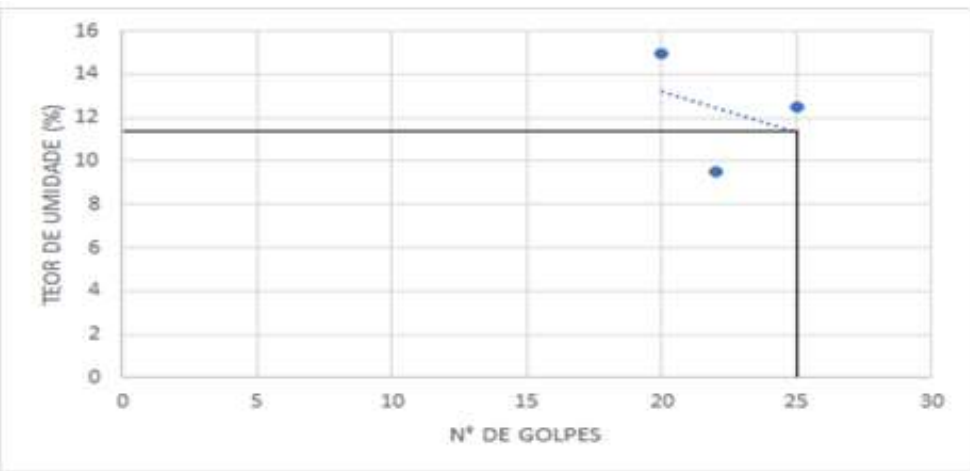

Figura 12: Determinação do limite de liquidez da Cava 2. 


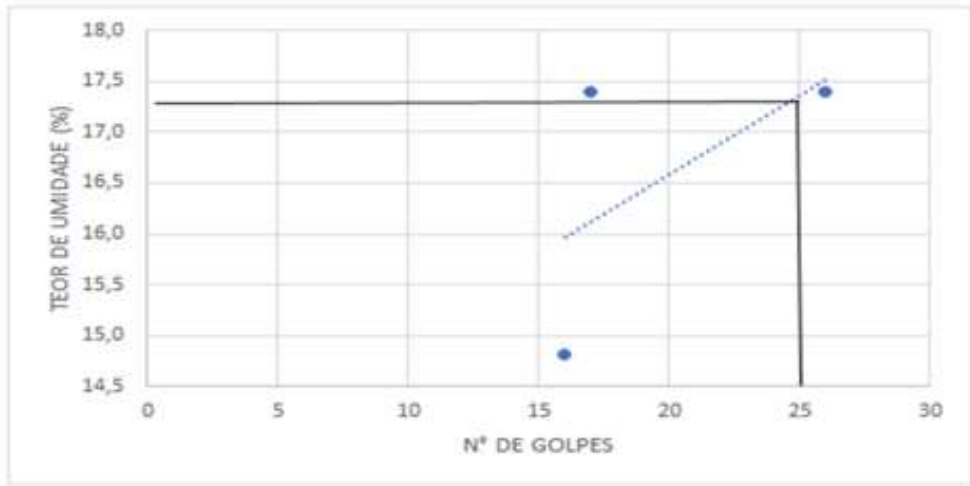

Figura 13: Determinação do limite de liquidez da Cava 3.

Com a utilização das Figuras 11, 12 ,13 foi possível a determinação dos valores dos limites de liquidez das Cavas 1, 2 e 3, sendo seus valores aproximadamente 13,35\%, 11,8\% e 17,4\% respectivamente. Observase a notoriedade do conhecimento da relação entre o teor de umidade e o limite de plasticidade, pois, à medida que se acrescenta água, o solo adquire características mais líquidas, sendo assim, maior capacidade de ser moldado. Para o solo analisado, como forma de alcançar o teor de umidade natural do solo, foram pesadas amostras de $4 \mathrm{~kg}$ para cada escavação e foram levadas para a estufa com a temperatura interior de $105^{\circ} \mathrm{C}$ por um período de 24 horas. Ao serem retiradas, as amostras foram novamente pesadas e registradas como possuindo uma massa de solo seco igual a $3,65 \mathrm{~kg}$. O teor de umidade (w) natural foi determinado como sendo, a diferença entre o solo úmido e seco, dividido pelo peso total inicial, sendo assim, com o uso da Equação (3).

$$
\mathrm{w}=\frac{4-3,65}{4 \times 100} \quad \mathrm{w}=8,75 \% \quad \text { Eq (3) }
$$

Como o teor de umidade natural é inferior ao menor entre os limites de liquidez, que é $11,8 \%$, as partículas argilosas do solo apresentam-se com estando em seu estado semissólido, porém, devido a pequena porcentagem desses grãos em relação às areias, não influencia na estrutura do poço a ser adotada quando o solo sofrer atuação da água sobre ele.

O ensaio para a determinação dos limites de plasticidade das amostras fora inviabilizado devido à ausência de um gabarito com $3 \mathrm{~mm}$ de diâmetro e $10 \mathrm{~cm}$ de comprimento, ou seja, incapacitando um correto molde dos corpos de prova. Diante disso, foi pesquisado meios empíricos de determinar os limites de plasticidade a partir de dados obtidos nos ensaios de peneiramento e de limites de plasticidades das amostras. Segundo Das et al. (2014), se após a realização dos ensaios de peneiramento, uma porcentagem mínima de $30 \%$ não passar pela peneira de $0,075 \mathrm{~mm}$, pode-se descartar a classificação desse solo do tipo argiloso, não havendo a necessidade da determinação dos limites de consistência.

\section{Determinação do Índice Pluviométrico}

Deve-se e ter um conhecimento dos índices pluviométricos de cada localidade, de modo que assim sejam dimensionados corretamente sistemas de infiltração que suportem essas lâminas d'água, reduzindo o escoamento superficial e resolvendo grande parte dos problemas de alagamentos. $\mathrm{O}$ valor do índice pluviométrico que seria adotado para este trabalho teria como valor, a máxima precipitação em um período 
histórico de 30 anos, que seria fornecido pelo sítio da Agência Nacional de Águas (ANA). O local estudado fica entre duas bacias, nas quais serviriam para o cálculo da bacia pertencente a tal, porém uma delas teve seus dados fornecidos incorretamente, o que inviabiliza tal adoção, segue figuras que demonstram a relação do ponto estudado com a localização fornecida na ANA, como também a tabela com falhas em seus elementos. Na Figura 14 abaixo é possível observar os pontos onde estão localizadas as estações de estudo.

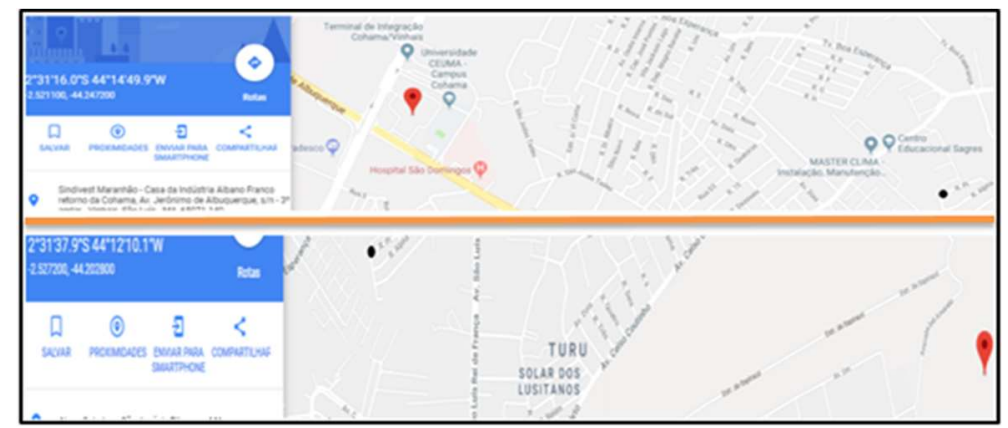

Figura 14: Localização das estações em relação ao local de estudo.

Os pontos vermelhos que servem para demarcar o local a partir das localizações fornecidas na ANA e o ponto preto é o local de estudo, que fica no Residencial Farol de São Marcos, bairro Turu. Na Figura 15 a seguir é atestado o erro nos registros realizados em uma das bacias, que além de não possuir a série história, nem os meses ou dias das marcações, as medições das chuvas estão zeradas, valores esses que se encontram dentre do retângulo preto feito na Figura abaixo.

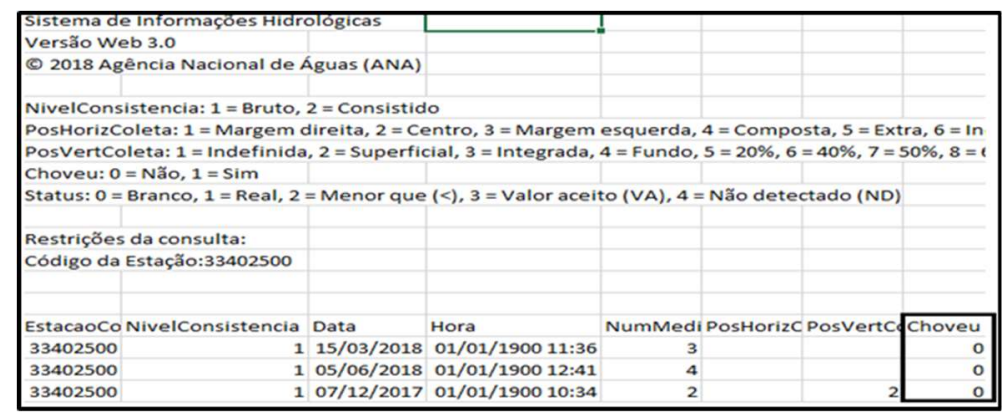

Figura 15: Print screen do sítio da ANA (2018).

Como é impossibilitado o uso dos dados fornecidos pela ANA para obtenção do índice pluviométrico da região em estudo, será utilizado o método da curva (IDF) de intensidade, duração e frequência. Para os autores Pereira et al. (2017), falam que as curvas IDF nada mais são, que curvas geradas pela relação de grandezas obtidas a partir de dados locais, onde tem-se a ocorrência das chuvas, tais como, o tempo de recorrência daquela precipitação máxima e da duração da mesma, gerando assim um valor possível de máxima intensidade, que é dada pela Equação 4 abaixo.

$$
\mathrm{I}=(\mathrm{K} * \mathrm{TR}) \mathrm{a} /(\mathrm{t}+\mathrm{b}) \mathrm{c}
$$

Sendo que 'i' é a intensidade máxima possível de chuva, que é determinada a partir da utilização de parâmetros como, K, a, b e c, que são ajustados com bases dos volumes de chuva do local de estudo, o TR, que é o tempo de retorno, ou seja, em quanto tempo aquela precipitação máxima poderá ocorrer 
novamente, dada em anos e o fator tempo, que quer dizer o tempo em minutos que essa chuva ocorreu (RIBEIRO et al., 2015). Substituindo os valores dos coeficientes na Equação (4) acima o resultado obtido de intensidade máxima é $\mathrm{l}=210,02 \mathrm{~mm} / \mathrm{h}$.

\section{Dimensionamento}

A priori terá o dimensionamento de um poço de infiltração, para determinação do volume possível que ele irá captar, armazenar e infiltrar, durante um período de chuva. Inicialmente haverá o prédimensionamento, no qual serão adotadas medidas, tais como, 1 metro para o diâmetro do poço, e como profundidade será adotada a cota de $1,4 \mathrm{~m}$, que é a mesma do final da escavação feita no ensaio para determinar a taxa de percolação. O valor da taxa de percolação, diante dos ensaios realizados em campo, será de $0,010120 \mathrm{~m} / \mathrm{h}$. Além disso, como na NBR 10844:1989, fornece uma tabela de intensidade pluviométrica para uma precipitação com duração de 5 minutos, para o poço a ser projetado, terá que armazenar esse fluido nesse mesmo intervalo, ou seja, o tempo a ser utilizado será de 0,083h.

Para a determinação da área total a ser utilizada na equação geral do volume de um poço, determinado pela Eq 5 abaixo, leva-se em consideração que a infiltração da água através do sistema que será implantado, ocorrerá pelas áreas de sua lateral e base, sendo assim, a área total de um poço.

$$
\mathrm{AT}=\left(\left(\pi \cdot \mathrm{d}^{2}\right) / 4\right)+(\pi \cdot d \cdot h)
$$

Onde, ' $d$ ' é o diâmetro e ' $h$ ' é a altura, sendo valores pré-determinados e que de acordo com as necessidades podem sofrer modificações no projeto, de modo a se obter o volume do poço necessário para captar e infiltrar as águas provenientes do escoamento superficial. Utilizando a Eq (5) o solo terá como área total AT de $5,19 \mathrm{~m}^{2}$.

Em seu trabalho Peixoto (2011), fornece um meio de calcular o volume de água que um poço será capaz de armazenar e infiltrar, que é a partir de suas dimensões já pré-definidas, além de ser levado em consideração a taxa de percolação do solo , a área total que sofrerá o impacto pelo escoamento superficial e que deverá ter como destinação o dispositivo e o período da precipitação, através da equação geral do volume total de um poço necessário para captar a água durante um certo período de precipitação utilizando a Equação (6).

$$
\mathrm{V}(\mathrm{t})=6,12 \times \mathrm{Ks} \times \mathrm{AT} \times \mathrm{t} 0,89
$$

Sendo que o 'Ks' é a taxa de percolação do solo, o 'AT' é a área total de um poço, sendo a somatória da área da base e da área lateral do mesmo e ' $t$ ' é o tempo em que a chuva ocorreu. Substituindo os valores nessa Equação (6), o poço terá como volume de $0,0351 \mathrm{~m}^{3}$. Diante do volume obtido, o poço tem a capacidade de armazenar 35,1l decorrentes da precipitação com duração de 5 minutos, que é o mesmo que 7,02L a cada minuto.

\section{Determinação da quantidade de poços}

A quantidade de poços a serem implantados em determinada localidade é resultante da quantidade de volume a ser armazenado a partir da vazão de projeto, de modo que o mesmo estoque todo fluido, não 
havendo assim o acumulo na superfície. Para determinação da vazão de projeto (Q) tem-se primeiramente que determinar a área de atuação da chuva que fornecerá água para os pontos de futura implantação dos poços. A área de contribuição da bacia que atuará sobre o ponto de estudo foi calculada pelo Google Earth, como na Figura 16 a seguir:

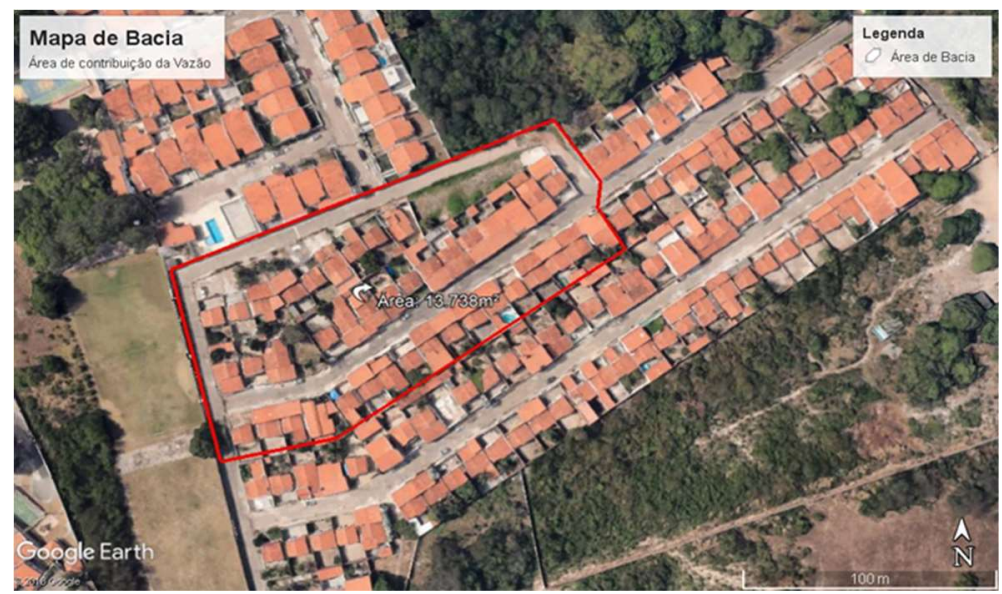

Figura 16: Área drenante da bacia.

Na Figura 16 acima a área da bacia a ser utilizada para cálculo da vazão será de $13.738 \mathrm{~m}^{2}$ que é o mesmo que $0,013738 \mathrm{~km}^{2}$. O valor do coeficiente de escoamento superficial para a bacia estudada, com base na Tabela 2, será de $C=0,8$, pois, ela está localizada em uma área com elevada densidade de edificações, e com ruas possuindo camadas asfálticas. Na tabela fornecida por Ribeiro et al. (2015), possuem duas linhas com os parâmetros a serem substituídos na Equação 4 acima para a cidade de São luís, fornecendo assim dois valores distintos para a intensidade de precipitação, como na Figura 17.

\begin{tabular}{|llccccccc|}
\hline Código & Municipio & Latitude & Longitude & $\mathrm{K}$ & $\mathrm{a}$ & $\mathrm{b}$ & $\mathrm{c}$ & $\mathrm{r}^{2}$ \\
\hline 00245005 & Pinheiro & $-2,517$ & $-45,083$ & $\$ 62,180$ & 0,151 & 10 & 0,742 & 0,994 \\
00344004 & Cantanhede & $-3,633$ & $-44,376$ & 1080,190 & 0,155 & 10 & 0,742 & 0,994 \\
00245011 & Santa Helena & $-2,274$ & $-45,271$ & 1016,480 & 0,229 & 10 & 0,742 & 0,988 \\
00244002 & São José do Ribamar & $-2,550$ & $-44,067$ & 976,340 & 0,169 & 10 & 0,742 & 0,993 \\
00244006 & São Luís & $-2,883$ & $-44,350$ & 1205,310 & 0,163 & 10 & 0,742 & 0,993 \\
00244007 & São Luís & $-2,533$ & $-44,300$ & 1089,680 & 0,138 & 10 & 0,742 & 0,995 \\
00245006 & Santa Helena & $-2,233$ & $-45,300$ & 1579,790 & 0,207 & 10 & 0,742 & 0,990 \\
\hline
\end{tabular}

Figura 17: Parâmetros K, a, b, c da equação de intensidade-duração-frequência.

Tabela 5: Determinação da intensidade pluviométrica.

\begin{tabular}{|l|l|l|l|l|l|l|}
\hline $\mathbf{K}$ & a & B & C & TR (anos) & tc (min) & Im (mm/h) \\
\hline 1205,00 & 0,16 & 10,00 & 0,74 & 5,00 & 5,00 & $\mathbf{2 1 0 , 0 2}$ \\
\hline 1089,68 & 0,14 & 10,00 & 0,74 & 5,00 & 5,00 & $\mathbf{1 8 2 , 4 3}$ \\
\hline
\end{tabular}

Legenda: Valores dos parâmetros $k, a, b, c$ utilizando o tempo de recorrência (TR) e tempo de concentração (tc).

Sendo assim, o valor adotado de intensidade de precipitação com o usa da Equação 4 é $\mathrm{I}=210,02 \mathrm{~mm} / \mathrm{h}$. 
Tendo já determinada a intensidade da chuva, a área de drenagem e o coeficiente de escoamento superficial, e que a área de atuação é inferior a $3 \mathrm{~km}^{2}$, usa-se o método racional para cálculo de contribuição da bacia. A delimitação da bacia de contrição, ou seja, a área que receberá precipitação em determinada bacia, influencia diretamente na forma de calcular a vazão de projeto, pois, com bases nessas áreas, será determinada um tipo de equação para cada uma e assim definida a vazão de projeto, como por exemplo o método racional, que é utilizado para bacias com áreas menores que $3 \mathrm{~km}^{2}$ (TOMAZ, 2002). Na Equação 7 abaixo temos:

$$
Q=0,278 \times C \times I \times A
$$

Onde, C é o coeficiente de escoamento superficial, que leva em consideração características da mesma, sendo seus valores são tabelados, 'l' é a intensidade máxima de precipitação atuante sobre a bacia e ' $A$ ' é a área de drenagem. Fazendo a substituição dos dados tem-se como vazão do projeto $Q=38,471 / \mathrm{min}$. Por fim, considerando que o poço dimensionado anteriormente tem a capacidade de armazenamento igual a 7,02 litros a cada minuto, a quantidade de necessários para a total captação do escoamento superficial são de 6 poços de infiltração.

\section{CONCLUSÕES}

Diante dos resultados dos experimentos realizados tanto em campo como em laboratório, pode-se determinar que, o solo é composto em torno de $90 \%$ por partículas de areia, porém, como demonstra o resultado dos ensaios que definiram a taxa de percolação do mesmo, ele possui baixo grau de permeabilidade, o que é um dos fatores na baixa percolação da água nos períodos de chuvas, como também, a inexistência de sistemas de microdrenagem no local estudado, como por exemplo, bocas de lobo.

Como a área da vizinhança que faz contribuição de fluidos, origina um escoamento superficial superior à permissibilidade de percolação do solo, ocasiona assim o surgimento dos alagamentos. Sendo assim, há a necessidade da implantação de sistemas de infiltração, no caso, os poços de infiltração. Com posse dos dados obtidos dos ensaios, foi dimensionado um poço com altura de 1,4 metros de profundidade e 1 metro de diâmetro, possuindo um volume capaz de armazenar e infiltrar 7,02 l/min, e diante da vazão de projeto que é 38,47litros / min, tem-se necessidade de implantação de 6 poços de infiltração para solucionar os problemas de inundações na localidade do Residencial Farol de São Marcos.

\section{REFERÊNCIAS}

ABNT. Associação Brasileira de Normas Técnicas. NBR 10844: Instalações prediais de águas pluviais. Rio de Janeiro: ABNT, 1989.

ABNT. Associação Brasileira de Normas Técnicas. NBR 13969: Tanques sépticos: unidades de tratamento complementar e disposição final dos efluentes líquidos. Projeto, construção e operação. São Paulo: ABNT, 1997.

ABNT. Associação Brasileira de Normas Técnicas. NBR 6457: Amostras de solo- Preparação para ensaios de compactação e ensaios de caracterização. Rio de Janeiro: ABNT, 2016.
ABNT. Associação Brasileira de Normas Técnicas. NBR 6459: Solo: Determinação do limite de liquidez. Rio de Janeiro: ABNT, 2016.

ABNT. Associação Brasileira de Normas Técnicas. NBR 9603: Sondagem a Trado- Procedimento. Rio de Janeiro: ABNT 2015.

ABNT. Associação Brasileira de Normas Técnicas. NBR 6484: Solo: Sondagem de simples reconhecimento com SPT: Método de ensaio. Rio de Janeiro: ABNT, 2001.

BRITO, D. S.. Metodologia para seleção de alternativas de 
sistemas de drenagem. Dissertação (Mestrado em Tecnologia Ambiental e Recursos Hídricos) - Universidade Brasília, Brasília, 2006.

CARVALHO, D. F.; SILVA, L. D. B.. Hidrologia. 2006.

CAPUTO, H. P.. Mecânica dos solos e suas aplicações. Rio de Janeiro: LTC, 1988.

DAS, B. M; SOBHAN, K. Fundamentos de Engenharia Geotécnica. 8ed. São Paulo: Cengage Learning, 2014.

FERREIRA, T. S.. Avaliação do comportamento hidrológico de poços de infiltração de águas pluviais sob diferentes concepções. Dissertação (Mestrado) - Universidade Federal de São Carlos, São Carlos, 2016.

TOMAZ, P.. Cálculos Hidrológicos E Hidráulicos Para Obras Municipais. Guarulhos, 2002.
TUCCI, C. B. J.. Inundações urbanas na américa do sul. Porto Alegre: Associação Brasileira de Recursos Hídricos, 2003.

PEREIRA, D. C.; DUARTE, L. R.; SARMENTO, A. P..

Determinação da curva de intensidade, duração e frequência do município de Ipameri-Goiás. Revista Eletrônica de Engenharia Civil, v.13, n.12, p.14, 2017. DOI: https://doi.org/10.5216/reec.v13i2.43330

PEIXOTO, V. C.. Análise paramétrica e dimensionamento de poços de infiltração para fins de drenagem urbana. Dissertação (Mestrado em Área de Concentração em Geotecnia) - Escola de Engenharia de São Carlos, São Paulo, 2011.

RIBEIRO, A.; ANJOS, J. C. R.; SANTOS, G. G.; STEFANOSKI, D. C.. Equações de intensidade de chuvas para o estado do maranhão. Revista engenharia na agricultura, Viçosa, v.23, n.5, p.435-447, 2015.

A CBPC - Companhia Brasileira de Produção Científica (CNPJ: 11.221.422/0001-03) detém os direitos materiais desta publicação. Os direitos referem-se à publicação do trabalho em qualquer parte do mundo, incluindo os direitos às renovações, expansões e disseminações da contribuição, bem como outros direitos subsidiários. Todos os trabalhos publicados eletronicamente poderão posteriormente ser publicados em coletâneas impressas sob coordenação da Sustenere Publishing, da Companhia Brasileira de Produção Científica e seus parceiros autorizados. Os (as) autores (as) preservam os direitos autorais, mas não têm permissão para a publicação da contribuição em outro meio, impresso ou digital, em português ou em tradução. 